\title{
Implantable Glucose Biosensor with Enhancing Electron Transfer - Nanocomposite Functional Layers
}

\author{
Xianying Zhang, Qiyu Wang* \\ Institute of Physics, Chinese Academy of Sciences, Beijing 100190, China \\ *E-mail: qywang10@iphy.ac.cn \\ doi: $10.20964 / 2021.01 .77$
}

Received: 22 September 2020 / Accepted: 11 November 2020 / Published: 30 November 2020

\begin{abstract}
A nanocomposite of ferrocenecarboxylic acid (FcA), graphene oxide (GO), chitosan (CS) and glucose oxidase (GOD) has been developed and used as the functional component of a needle-type implantable glucose biosensor. GOD was successfully immobilized in a single step without any crosslinking agents; and the enzymatic function and specificity was preserved. The biosensor morphology was characterized by scanning electron microscopy (SEM), and the functional properties were examined electrochemically. We showed that our glucose biosensor exhibited a fast response with high reproducibility and stability. A linear response to glucose - which was mostly undisturbed by common interfering species - was obtained between glucose concentrations between 0.01 to $10 \mathrm{mM}$. The detection limit and sensitivity of our biosensor were $19 \mu \mathrm{M}$ and $8 \mathrm{~mA} \mathrm{~cm}^{-2} \mathrm{mM}^{-1}(\mathrm{~S} / \mathrm{N}=3)$, respectively.
\end{abstract}

Keywords: ferrocenecarboxylic acid, graphene oxide, chitosan, glucose oxidase, needle-type biosensor

\section{FULL TEXT}

(C) 2021 The Authors. Published by ESG (www.electrochemsci.org). This article is an open access article distributed under the terms and conditions of the Creative Commons Attribution license (http://creativecommons.org/licenses/by/4.0/). 